\title{
APPLICATION OF RISK ANALYSIS RESULTS IN EMERGENCY PLANNING OF A NUCLEAR POWER PLANT
}

\author{
J.-U. KLÜGEL ${ }^{1}$, D. PAPINI ${ }^{1} \&$ B. ASKARI ${ }^{2}$ \\ ${ }^{1}$ NPP Goesgen, Switzerland. \\ ${ }^{2}$ SwissSafeTech, Ltd., Switzerland.
}

\begin{abstract}
NPP Goesgen developed a full-scope probabilistic risk assessment (PRA) model, allowing for an estimate of the risk of offsite consequences. The model considers all operational modes of the plant, power operation, low power operation and shutdown conditions and all risk-relevant initiating events that may lead to a plant accident. The model allows computing different risk metrics starting from core damage frequency, frequency of a large offsite release to detailed plant damage states, activity release categories as well as the risk of offsite consequences expressed in radiological health effects. The risk model is programmed in the software system RISKMANTM in the format of a set of linked event trees with associated fault trees. Analysis tools for the estimation of accident progression and offsite consequences support the model. A plant-specific simulator for severe accidents is in use, which is based on the MELCOR code. Off-site consequences in terms of dose levels are calculated using the MACCS 2.0 code. The full power models are used to support emergency planning by providing information on the possible consequences of hypothetical accidents in dependence on weather conditions. In cooperation with the responsible governmental agencies, this allows to support evacuation actions in case of severe accidents. Simple cartographic aids are available for emergency planning accounting for a possible loss of offsite power during an emergency, preventing the use of computational tools.

The paper presents the methodology and key insights of the risk assessment of offsite consequences for NPP Goesgen and demonstrates the use of the results in emergency planning.

Keywords: emergency planning, nuclear power plant, radiological consequences, risk analysis.
\end{abstract}

\section{INTRODUCTION}

The application of probabilistic risk analysis (PRA) in nuclear technology has a long history. First, the applications were related to the development of risk-informed site criteria, providing a basis for the selection of sites for nuclear power plants in an industrial scale (e.g. Farmer's siting criteria [1]). The United States Nuclear Regulatory Commission's reactor safety study (WASH-1400 [2]) represented the first large-scale and systematic risk assessment for nuclear reactors, allowing for comparing risks of nuclear energy to other industries. Since then, PRA or probabilistic safety analysis (PSA; used as a synonym in Europe) became a valuable safety assessment tool complementary to traditional deterministic safety analysis. In general, the approaches used in practice follow the benchmarking publication of Kaplan and Garrick [3]. Here, risk is evaluated in terms of a discrete probability distribution as a set of discrete triplets (scenarios $\mathrm{S}_{\mathrm{i}}$, associated probabilities $\mathrm{p}_{\mathrm{i}}$ and consequences $\mathrm{C}_{\mathrm{i}}$ ), taking into account the uncertainties related to the assessment of scenario probabilities and consequences. Plant-specific PSA studies for nuclear power plants are categorized by their level of completeness and the metrics that are used for the assessment of consequences. With respect to risk metrics, PSA studies are categorized into three different levels (levels 1-3). PSA studies level 1 use the (reactor) core damage frequency as the main risk metric for the consequences of nuclear accidents. PSA studies level 2 use the frequency of large radioactivity releases as the main risk metric. PSA studies level 3 estimate the consequences of nuclear accidents directly in terms of early and late fatalities (health effects) as well as economic losses in 
monetary units. With respect to the degree of completeness, PSA studies are distinguished by the scope of postulated initiating events (PIE) and different operating modes that are taken into account. With respect to PIE, we distinguish between internal events (caused by system failures), external hazards (e.g. earthquakes and external floods) and internal hazards as, for example, fires and internal floods. The operational modes of a nuclear power plant range from full power operation to different modes of non-power operation.

The range of risk-informed applications for nuclear power plants has grown largely, since risk analyses were accepted as part of the regulatory framework [4] in USA. References [5, 6] give an overview on PSA applications in different countries.

NPP Goesgen completed its first all initiating events and hazards, all operational modes PSA study up to level 2 in 1994. Since then, NPP Goesgen has completed several updates of the study to address plant modifications, new emergency procedures, as well as new assessments of natural hazards (earthquakes, floods, extreme rainfall, wind and tornado). As part of the Post-Fukushima Safety Reassessment Programme, NPP Goesgen completed its first PSA level 3 study in 2013. The analysis of possible health effects of severe accidents was the main purpose of the study. The study was updated in 2018. The new study results were used to support the NPP Goesgen emergency organization by developing tools for a quick assessment of offsite radiological consequences of severe accidents.

\section{SCOPE, METHODS AND INSIGHTS FROM NPP GOESGEN PSA LEVEL 3}

A PSA level 3 model is directly based on the preceding steps of risk assessment, the PSA level 1 and level 2 models and results. Therefore, a short summary of the corresponding methods and results is provided first. Radiological and health risks for a nuclear power plant are significantly higher at full power operation. Therefore, this summary is focused on this operational mode.

2.1 Summary of methods, results and insights from the Goesgen PSA level 1/level 2 studies

Generally spoken, the PSA model of a nuclear power plant represents a large logical model. This logical model maps a set of initiating events (the input) leading to a transient response of plant systems to the outcome(s) of interest. These outcomes for a level 1 PSA are typically:

- the frequency of core damage (CDF) including its associated uncertainty and

- the frequency of specific plant damage states (PDSs) including their associated uncertainties.

While the CDF is used as the most important risk metric for a level 1 PSA, the PDSs allow for a deeper analysis of the plant response, by grouping different accident sequences leading to a similar response into common bins. The NPP Goesgen model uses a set of 155 different PDSs addressing different aspects of plant response. The typical outcomes for a level 2 PSA as used in the Goesgen PSA are:

- the frequency of a large early release of radioactivity (LERF) and its associated uncertainty; LERF is a surrogate risk metric for assessing early health effects;

- the frequency of a large late release of radioactivity (LLRF) and its associated uncertainty; LLRF is a surrogate risk metric for assessing late health effects; 
- the combination of the frequencies of large early and large late releases, the large release frequency (LRF) and

- the frequency of different release categories (RCs) and their associated uncertainties.

The quantitative definition of the term 'large release' is different in different countries. Therefore, results of level 2 PSA studies for different plants and different countries cannot be compared frequently. The Goesgen PSA follows the definition provided in guideline A05 of the Swiss Nuclear Safety Inspectorate (ENSI). Correspondingly, a large release of radioactivity is a release exceeding either $2 \times 10^{15} \mathrm{~Bq}$ of Iodine- 131 or $2 \times 10^{14} \mathrm{~Bq}$ of Caesium- 137 .

The disadvantage of using surrogate risk metrics with respect to the characterization of health effects is that the radiotoxicity of different release source terms, made up of different radionuclides as well as the different paths for the release of radioactivity into the environment, cannot be taken into account. By defining a set of RCs with associated source terms, a finer representation of radioactivity releases can be achieved. The RCs, if properly defined, provide the input for a later PSA level 3 development. The Goesgen model uses 14 different RCs, which differ by release path, release time and the associated source term made up of quantitatively different assemblies of radionuclides. By combining them appropriately, the key RCs (LERF, etc.) can be calculated.

Goesgen uses an integrated level 1/level 2 PSA model. This has the advantage that functional dependencies, as well as dependencies between the technical response of systems and the response of operating personnel as well as dependencies between different operator actions can be modelled directly. The PSA logical model was modelled using the RISK$\mathrm{MAN}^{\mathrm{TM}}$ software [7]. RISKMAN is a large event tree small fault tree code. It has many advanced properties and additional supporting tools like an integrated data analysis tool, an integrated Markov modelling tool, an integrated mini risk monitor feature and an advanced tool to support risk analysis for external hazard analysis. It provides high flexibility for modelling dependencies by using linked event trees and by modelling the dependencies by Boolean logics supported by a special script language. The main PSA software is complemented by a set of supporting 'deterministic' tools. With respect to PSA level 2 applications and a further PSA level 3 development, the Goesgen-specific severe accident simulator MELSIM (a MELCOR [8]-based application) is of special importance. This code allows for performing plant-specific analyses of the transient behaviour of a nuclear power plant during a severe accident, including the response of the reactor containment with respect to typical phenomena of severe accidents. Additionally, it allows for the evaluation of source terms of radioactivity releases for different accidents scenarios.

The detailed RCs characterized by frequency, the associated uncertainty and the source term made up of 10 different classes of radionuclides represent the main input to the level 3 PSA. The dominating risk contributors to the operational risk of NPP Goesgen are seismic hazards, internal fires, extreme high wind and tornadoes, as well as high-speed aircraft crashes. Due to the design of NPP Goesgen (a Siemens-KWU design with a high level of redundancy of safety systems), internal initiating events caused by system failures or pipe breaks leading to loss-of-coolant accidents are of significantly lower importance. The high importance of external events in the risk of nuclear power plant was known before the accident of Fukushima. The Fukushima disaster confirmed these insights from PSA studies.

The total CDF for full power operation for NPP Goesgen is below $10^{-5} / \mathrm{a}$, thus meeting the international requirements even for the risk profile of new reactor builds, while the LERF 


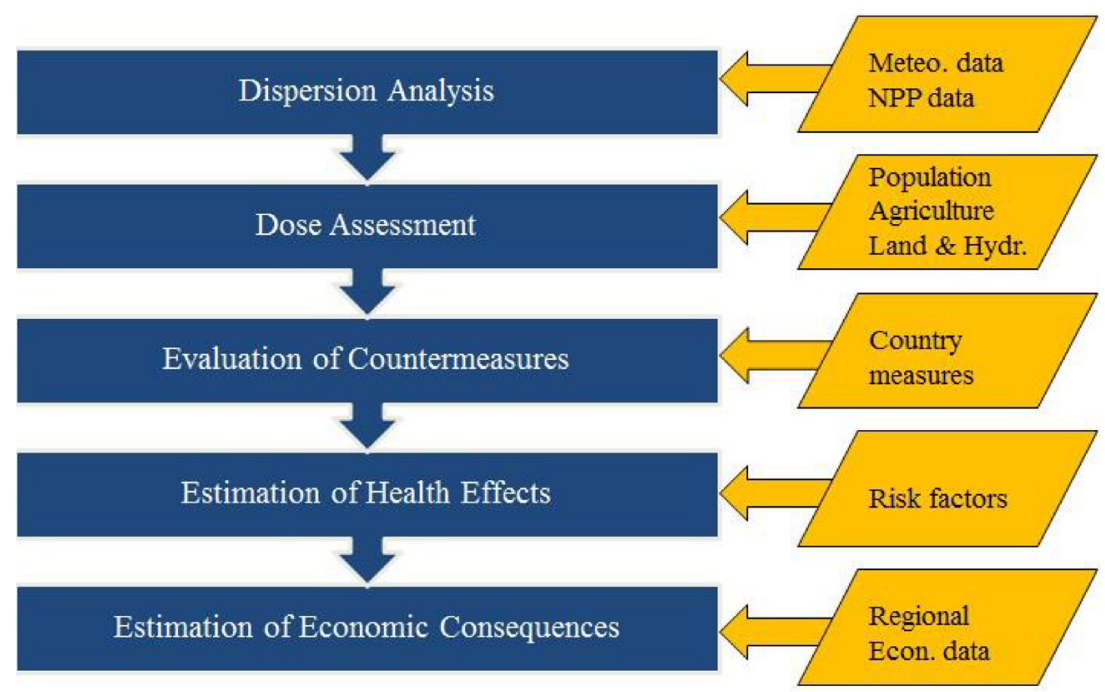

Figure 1: Major steps of the development of a level 3 PSA.

calculated, as defined by the Swiss regulatory guidelines, is about $3 \times 10^{-6} / \mathrm{a}$. This is higher than for new builds and is mainly driven by external hazards, especially seismic events.

\subsection{Methods and data for the development of Goesgen level 3 PSA}

The major steps of the development of a level 3 PSA are shown in Fig. 1. The evaluation of economic consequences was excluded from the scope of Goesgen level 3 PSA.

The development of a PSA level 3 model requires data, which on one hand provides the link to the precedent steps of PSA model development and on the other hand allows computing the offsite consequences of radioactivity releases to the environment. The following data are typically required.

\subsubsection{Source term data}

Source term data are provided by the results of the level 2 PSA in the format of RCs [9] with their associated frequency and uncertainties, release time, rate of energy release, release duration and release path.

For conservative risk assessment, as it is the case for many applications, the number of RCs considered in the level 3 PSA is frequently reduced by screening according to risk importance and sensitivity analysis. The sensitivity scenarios studied bounded the variability of releases within each of the RCs. The risk contribution with respect to health effects of slow accident sequences leading to late releases was found to be negligible. Tables 1-3 show the nomenclature for denotation of RCs and the risk-important RCs selected for further analysis of the consequences.

\subsubsection{Spatial data, consequence analysis and meteorological data}

The Goesgen PSA level 3 study considers an area with a radius of $50 \mathrm{~km}$ around the site in the consequence analysis. All spatial data required are collected for this area. The data are collected for a spatial grid in polar coordinates $(\mathrm{r}, \theta)$ consisting of 16 compass sectors and 10 downwind distances. The population distribution is required for estimating the consequences of radioactivity releases around the plant. 
Table 1: Release category characterization (large releases).

\begin{tabular}{llll}
\hline $\begin{array}{l}\text { Release category } \\
\text { designator }\end{array}$ & Release pathway & LERF & N/A \\
\hline RCA & $\begin{array}{l}\text { Release via the secondary side } \\
\text { safety/relief valves or via a second- } \\
\text { ary side pipe break (unscrubbed } \\
\text { containment bypass) }\end{array}$ & RCA1L \\
$\begin{array}{l}\text { Release via a hole (structural } \\
\text { failure or unisolated pipe with } \\
\text { direct connection to the outside } \\
\text { atmosphere) to the environment }\end{array}$ & RCB1L & \\
& $\begin{array}{l}\text { Filtered release via an open } \\
\text { ventilation exhaust line through the } \\
\text { stack (filter with limited capacity) }\end{array}$ & RCC1L \\
RCC & $\begin{array}{l}\text { Release via the filtered containment N/A } \\
\text { system with failures to recover filter } \\
\text { capacity and failure of isolation } \\
\text { after containment depressurization } \\
\text { RCE }\end{array}$ & $\begin{array}{l}\text { Release via large bypass LOCA } \\
\text { sufficiently large to cause a large } \\
\text { early release }\end{array}$ & RCE2L \\
\hline RCJ & RCJ1L & N/A \\
\hline
\end{tabular}

Topographical data are used to estimate the wake effect due to the presence of large obstacles, hills and mountains. The deposition of aerosols can also be affected by the topography of the surroundings of the plant site. This information is useful for estimating the efficacy of offsite emergency measures, for example, to define escape ways for people leaving the area after an accident. For the same area, meteorological data are collected (hourly values of wind direction, wind speed, stability category, precipitation and mixing layer height).

Consequence analysis for the Goesgen level 3 PSA was performed by using the WINMACCS 3.11 [10] computer code. This is the Windows version of the MACCS 2.0 code [11]. The MACCS 2.0 code uses a Gaussian dispersion model for the propagation of radioactivity in the atmosphere.

For obtaining representative results, consequence analysis was performed for several years of data collection. Consequence analysis was performed for an average year calculated for the observation period from 1989 to 2008 and for single, representative years (2011 and 2018).

\section{SUMMARY OF PSA LEVEL 3 RESULTS}

\subsection{Source term analysis}

Detailed accident analysis was performed for all RCs leading to a large release of radioactivity. The results of these analyses allow characterizing the source term and the corresponding release paths. The plant-specific MELSIM [12] severe accident simulator (MELCOR-based computation engine [8]) was used for the analyses. Table 1 provides a characterization of the risk-relevant RCs. 
Table 2: Risk important accident scenarios.

\begin{tabular}{|c|c|c|c|}
\hline Case & $\begin{array}{l}\text { Release } \\
\text { category }\end{array}$ & Description & $\begin{array}{l}\text { Comment/ } \\
\text { probability (in } \\
\text { relative terms) }\end{array}$ \\
\hline RUN-03 & $\mathrm{RCB} 1 \mathrm{~L}$ & $\begin{array}{l}\text { High-speed military aircraft } \\
\text { crash leading to a TSBO and a } \\
\text { small break LOCA }\end{array}$ & $\begin{array}{l}\text { Very low probabil- } \\
\text { ity and high conse- } \\
\text { quences }\end{array}$ \\
\hline RUN-05 & $\mathrm{RCB} 2 \mathrm{~L}$ & $\begin{array}{l}\text { Strong earthquake leading to a } \\
\text { TSBO }\end{array}$ & $\begin{array}{l}\text { Representative } \\
\text { scenario for the NPP } \\
\text { Goesgen PSA level } \\
1 / 2 \text { risk profile lead- } \\
\text { ing to a late release }\end{array}$ \\
\hline RUN-15 & RCA1L & Massive SGTR & $\begin{array}{l}\text { Very low probabil- } \\
\text { ity and high conse- } \\
\text { quences }\end{array}$ \\
\hline RUN-16 & $\mathrm{RCC} 1 \mathrm{~L}$ & $\begin{array}{l}\text { Strong earthquake and TSBO } \\
\text { release via an impaired filtered } \\
\text { venting system }\end{array}$ & $\begin{array}{l}\text { Representative } \\
\text { scenario for the } \\
\text { NPP Goesgen PSA } \\
\text { level } 1 / 2 \text { risk profile } \\
\text { leading to an early } \\
\text { release }\end{array}$ \\
\hline RUN-02 & RCB1L & $\begin{array}{l}\text { Strong earthquake and TSBO } \\
\text { and failure of the containment } \\
\text { isolation system }\end{array}$ & $\begin{array}{l}\text { Representative } \\
\text { scenario for the } \\
\text { NPP Goesgen PSA } \\
\text { level } 1 / 2 \text { risk profile } \\
\text { leading to an early } \\
\text { release }\end{array}$ \\
\hline RUN-06 & RCA1L & SGTR (single tube) & $\begin{array}{l}\text { More likely alter- } \\
\text { native to RUN-15 } \\
\text { leading to an early } \\
\text { release }\end{array}$ \\
\hline RUN-14 & RCB1L & $\begin{array}{l}\text { Severe plant transient leading to } \\
\text { an early containment bypass }\end{array}$ & $\begin{array}{l}\text { Low probability and } \\
\text { high consequences }\end{array}$ \\
\hline
\end{tabular}

According to national regulations, a release within $10 \mathrm{~h}$ after the onset of reactor core damage is considered an early release. Besides the large (denoted by the designator L) ones, some small releases were also analysed. For the first PSA level 3 completed in 2013, 21 analyses were performed. For the update in 2018, a set of refined analyses for the risk-relevant accident scenarios with special importance for the offsite emergency management was completed. For these scenarios, additional sensitivity analyses were performed by varying diverse assumptions affecting the time of failure of important safety equipment. Overall, about 120 MELSIM computation runs were performed as part of the two risk studies. The most important scenarios are described in Table 2.

The source terms were characterized in terms of the 10 groups shown in Table 3. 
Table 3: Radionuclide groups of release source terms.

\begin{tabular}{|c|c|c|c|}
\hline Group & Group name & Abbreviation & Elements \\
\hline 1 & Noble gases & $\mathrm{Xe}$ & $\begin{array}{l}\mathrm{He}, \mathrm{Ne}, \mathrm{Ar}, \mathrm{Kr}, \mathrm{Xe}, \mathrm{Rn}, \\
\mathrm{H}, \mathrm{N}\end{array}$ \\
\hline 2 & Alkali metals & Cs & $\mathrm{Li}, \mathrm{Na}, \mathrm{K}, \mathrm{Rb}, \mathrm{Cs}, \mathrm{Fr}, \mathrm{Cu}$ \\
\hline 3 & Alkaline earths & $\mathrm{Ba}$ & $\begin{array}{l}\mathrm{Be}, \mathrm{Mg}, \mathrm{Ca}, \mathrm{Sr}, \mathrm{Ba}, \mathrm{Ra}, \\
\text { Es, Fm }\end{array}$ \\
\hline 4 & Halogens & I & $\mathrm{F}, \mathrm{Cl}, \mathrm{Br}, \mathrm{I}, \mathrm{At}$ \\
\hline 5 & Chalcogens & $\mathrm{Te}$ & $\mathrm{O}, \mathrm{S}, \mathrm{Se}, \mathrm{Te}, \mathrm{Po}$ \\
\hline 6 & Platinoids & $\mathrm{Ru}$ & $\begin{array}{l}\mathrm{Ru}, \mathrm{Rh}, \mathrm{Pd}, \mathrm{Re}, \mathrm{Os}, \mathrm{Ir}, \mathrm{Pt} \\
\mathrm{Au}, \mathrm{Ni}\end{array}$ \\
\hline 7 & $\begin{array}{l}\text { Early transition ele- } \\
\text { ments }\end{array}$ & Mo & $\begin{array}{l}\text { V, Cr, Fe, Co, Mn, Nb, } \\
\text { Mo, Tc, Ta, W }\end{array}$ \\
\hline 8 & Tetravalents & $\mathrm{Ce}$ & $\begin{array}{l}\mathrm{Ti}, \mathrm{Zr}, \mathrm{Hf}, \mathrm{Ce}, \mathrm{Th}, \mathrm{Pa}, \mathrm{Np}, \\
\mathrm{Pu}, \mathrm{C}\end{array}$ \\
\hline 9 & Trivalents & $\mathrm{La}$ & $\begin{array}{l}\text { Al, Sc, Y, La, Ac, Pr, Nd, } \\
\text { Pm, Sm, Eu, Gd, Tb, Dy, } \\
\text { Ho, Er, Tm, Yb, Lu, Am, } \\
\text { Cm, Bk, Cf }\end{array}$ \\
\hline 10 & Uranium & $\mathrm{U}$ & $\mathrm{U}$ \\
\hline
\end{tabular}

3.2 Plant-specific analysis of consequences

An analysis of consequences was done by WINMACCS. The release source terms are assigned to the corresponding isotope groups used as input data of the WINMACCS code. Totally, 55 isotope groups were used in the analysis of consequences. A Gaussian plume model models the dispersion of radioactivity to the environment. The WINMACCS code allows modelling several distinct plumes for each of the accident scenarios. Therefore, releases are set up by dividing release duration into different shorter periods; each constitutes a plume. A plume duration depends on release behaviour, which could be decided by plotting the cumulative release flow through the release (or leakage) position. Correspondingly, each of the releases is subdivided into a limited set of subsequent plumes. Each plume release is modelled as an instantaneous release occurring at the end time of the release phase modelled by the preceding plume. The first plume starts at the starting time of the accident. This approach ensures a conservative estimate of the radiological consequences. Typically, the releases are subdivided into three to four distinct plumes. Sensitivity analysis confirmed that a further subdivision does not affect the key results of the analyses. The plume rise depends on the energy content of the release. This information is part of the MELSIM output data.

The radiological consequences were evaluated within a downwind distance of $50 \mathrm{~km}$ around the Goesgen site for 160 spatial sectors.

Figures 2 and 3 show the computed radiation dose in the surrounding of the NPP for two different seismic event scenarios for the most critical weather condition. Figure 2 refers to an 


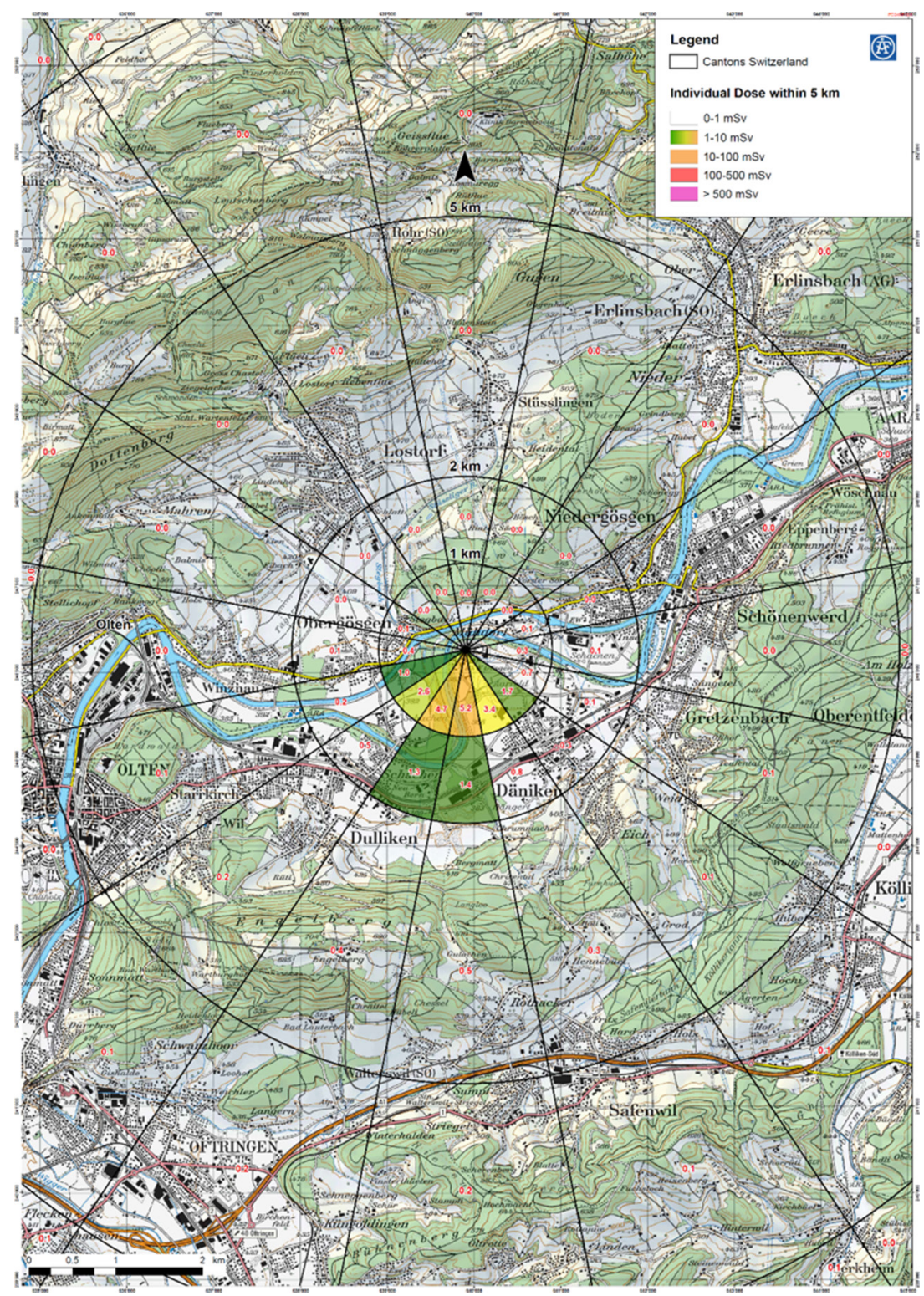

Figure 2: Radiation dose around the site (RUN-05, seismic event, late release).

accident scenario leading to a late release into the environment. This accident sequence is very characteristic of the outcome of a severe accident at the plant caused by a very strong earthquake. Such earthquakes by far exceed the design basis of the plant exceeding Peak Ground Acceleration (PGA) values of $0.6 \mathrm{~g}$. The overall risk contribution of such scenarios to health effects is very low. The highest radiation levels are computed for the near site area (less than $5 \mathrm{~km}$ ). The radiation levels computed for the most critical weather condition are below $10 \mathrm{mSv}$. This means that deterministic health effects (starting above a threshold value 


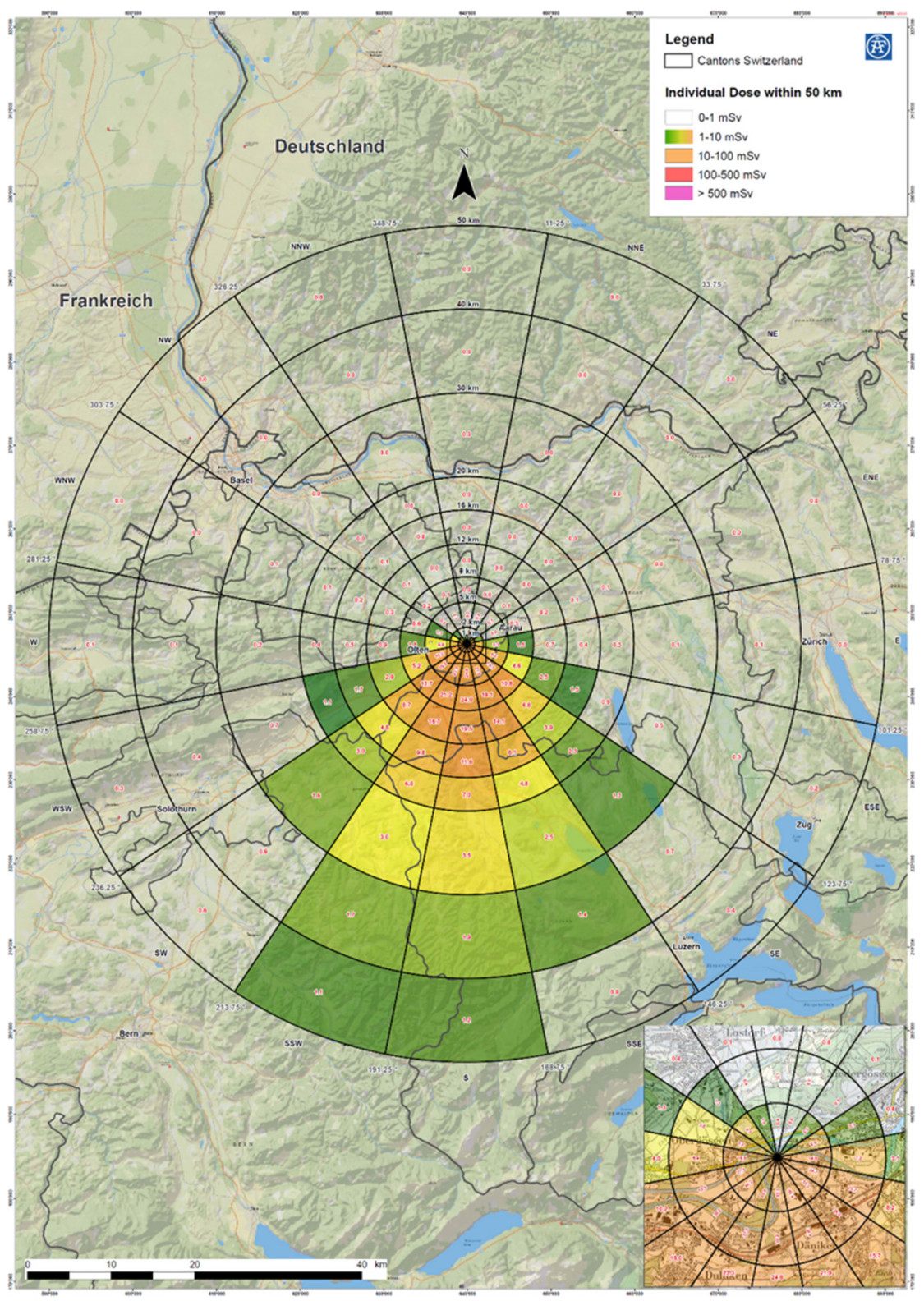

Figure 3: Radiation dose in the $50 \mathrm{~km}$ sector (RUN-16, seismic event, early release).

of $250 \mathrm{mSv}$ ) can be excluded. Figure 3 refers to a similar scenario leading to an (less likely) early release. Here, the computed radiation levels are higher, but still below $100 \mathrm{mSv}$. This means again that deterministic health effects can be excluded. As a summary, we can conclude that the most risk-important accident scenarios of the NPP Goesgen level 1/level 2 PSA almost do not contribute to the risk of adverse health effects (early fatalities or late cancer). This is a very important insight from the level 3 PSA. 


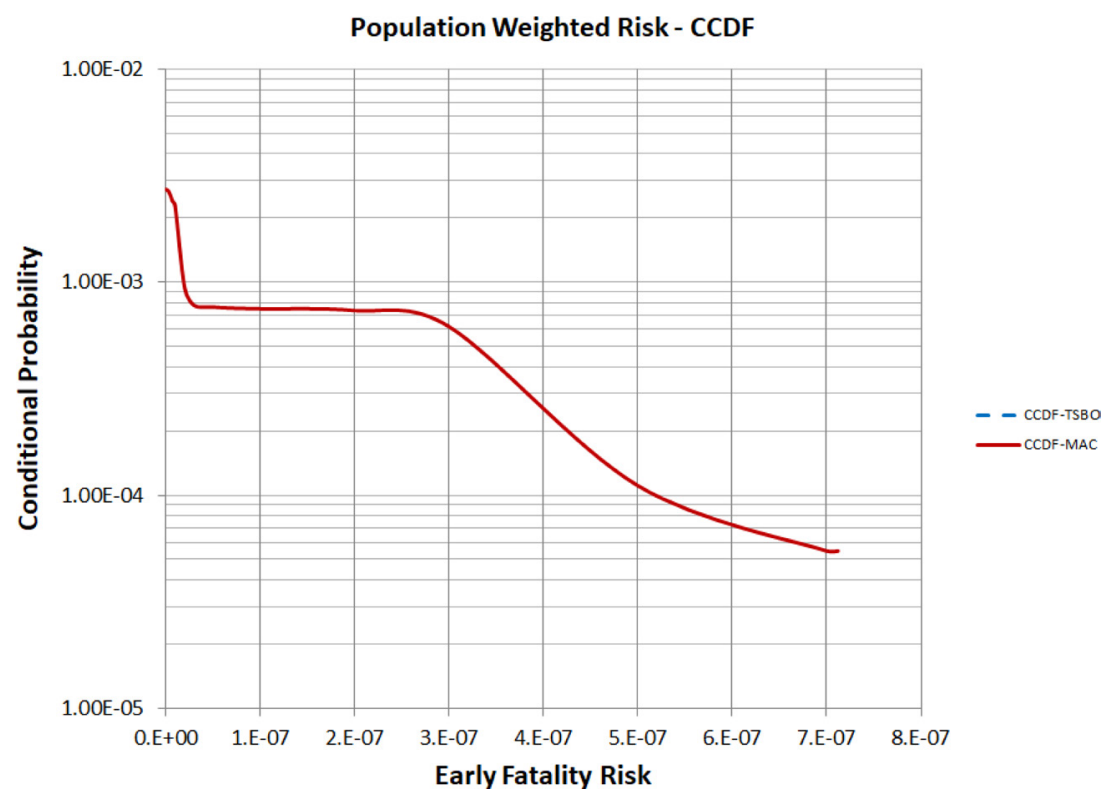

Figure 4: Population-weighted risk for early fatality (probability of an early fatality for an average person within $50 \mathrm{~km}$ distance of the plant).

\subsection{Main risk assessment results (health effects)}

PSA level 3 results have been presented in terms of complementary cumulative distribution functions (CCDFs). A CCDF typically provides a distribution of conditional probabilities corresponding to a given radiological consequence.

The CCDFs produced by the MACCS are based on the random sampling of a year of weather data. It is important to note that the evaluated conditional probabilities are conditional on the occurrence of an accident or a release event. Therefore, it is assumed that the probability of occurrence of an accident itself is one. The PSA level 3 risk results are driven by extreme and rare external events leading to an early failure of the reactor containment. The aircraft crash scenario (RUN-03) represents such an accident sequence. Figure 4 shows the population-weighted average risk for an airplane crash in comparison to a total station blackout (TSBO), caused by a seismic event. The risk, in general, is very low. The risk from the seismic event scenario is zero, and therefore does not even show up in the graph (blue-dotted line). The TSBO scenario belongs to the RCB2L release category, which is a late release (Table 1). In this case, there is no early fatality risk (deterministic health effect). Thus, the airplane crash scenario (denoted as MAC) drives the risk.

Another important output from the PSA level 3 consists in the evaluation of the maximum distance of early fatality risk greater than 0 . Table 4 shows that the risk of an early fatality after a severe accident is limited to the near site area of the plant.

\section{APPLICATION OF PSA LEVEL 3 RESULTS FOR OFFSITE EMERGENCY MANAGEMENT}

Results and insights gained from PSA level 3 are used to support offsite emergency management. Planning and execution of offsite emergency management in Switzerland is a 
Table 4: Maximum distance of early fatality risk >0 (reference year 2010).

\begin{tabular}{lll}
\hline Release category & Max. distance $(\mathbf{m})$ & Conditional probability \\
\hline RCA1L & 250 & $9.93 \mathrm{E}-02$ \\
RCB1L & 100 & $7.42 \mathrm{E}-03$ \\
RCC1L & 0 & 0 \\
RCB2L & 0 & 0 \\
\hline
\end{tabular}

governmental task [13] and in the responsibility of Swiss cantons. Operators of nuclear power plants have to support the planning of emergency actions by providing criteria for different emergency levels and information on the situation at the plant as well as on the possible consequences of an accident in case an accident occurred. The information required includes assessments of the radioactive source term as well as quick estimates of the radiological situation with respect to possible consequences. PSA level 3 and the supporting analysis tools MELSIM [12] and WINMACCS provide valuable tools to develop this information in the format of planning aids and calculation tools. The latter are used for quick assessments of the situation in case of an accident.

\subsection{Sensitivity studies for the assessment of the efficacy of offsite emergency actions}

According to the Swiss concept of emergency preparedness, there are two emergency zones. Zone 1 is limited to $5 \mathrm{~km}$, and the zone 2 border encompasses a circular region with a radius of $20 \mathrm{~km}$. A third zone (zone 3) is considered to be all the area outside of the emergency zones 1 and 2. Swiss emergency preparedness concept considers diverse countermeasures. The early phase after a severe accident includes sheltering (abbreviated as Shel. in Table 5), iodine tablets intake (within a radius of $20 \mathrm{~km}$, abbreviated as $\mathrm{KI}$ in Table 5) and, as a final consequence of large releases, evacuation (abbreviated as Evac. in Table 5). The long-term countermeasures, to provide a long time perspective of protection, are relocation, food bans and land decontamination. The short-term countermeasures were modelled as part of the WINMACCS model for NPP Goesgen. For sheltering, dose protection factors were considered in dependence on the location of sheltering and on the release phase (cloud release or ground phase). The intake of iodine tablets reduces the risk of deterministic health effects (cancer risk from the absorption of the iodine I-131). An easy assessment of the benefit of countermeasures can be performed by comparing the total population dose allocated to the population within specific settlement areas for scenarios with and without successful implementation of countermeasures. The results of such a comparison are shown in Table 5. The peak probability reflects the probability of the weather conditions that led to the peak population dose.

The results of the sensitivity study confirmed that a successful implementation of countermeasures leads to a reduction of population dose, and thus to a reduction of health risk. It was observed that this positive benefit is limited to extremely large early and thus extremely rare releases. For the more likely and risk-dominant scenarios of PSA level 1/level 2, it was found that countermeasures do not lead to a measurable reduction of health risks. On the contrary, sensitivity studies performed under the assumption that evacuation measures are implemented inadequately during the early phase (the cloud passage phase) showed a possible increase of health risks due to an increased exposure probability. 
Table 5: Population dose (RUN03, RCB1L).

\begin{tabular}{|c|c|c|c|c|}
\hline $\begin{array}{l}\text { Downwind } \\
\text { distance (km) }\end{array}$ & $\begin{array}{l}\text { Countermeas- } \\
\text { ure }\end{array}$ & Mean (Sv) & Peak (Sv) & $\begin{array}{l}\text { Peak } \\
\text { probability }\end{array}$ \\
\hline \multirow{3}{*}{$0.0-2.0$} & None & $6.00 \mathrm{E} 04$ & 4.97E05 & $1.37 \mathrm{E}-05$ \\
\hline & KI + Shel. & $2.55 \mathrm{E} 04$ & $1.88 \mathrm{E} 05$ & $1.37 \mathrm{E}-05$ \\
\hline & $\begin{array}{l}\text { KI + Shel. + } \\
\text { Evac. }\end{array}$ & $1.55 \mathrm{E} 03$ & $1.10 \mathrm{E} 04$ & $4.97 \mathrm{E}-6$ \\
\hline \multirow{3}{*}{$0.0-5.0$} & None & $1.60 \mathrm{E} 05$ & $9.57 \mathrm{E} 05$ & $1.69 \mathrm{E}-05$ \\
\hline & KI + Shel. & $6.58 \mathrm{E} 04$ & 4.03E05 & $2.41 \mathrm{E}-03$ \\
\hline & $\begin{array}{l}\text { KI + Shel. + } \\
\text { Evac. }\end{array}$ & 5.38E03 & $3.42 \mathrm{E} 04$ & 4.91E-06 \\
\hline \multirow{3}{*}{$0.0-20.0$} & None & 3.03E05 & $1.53 \mathrm{E} 06$ & $4.85 \mathrm{E}-04$ \\
\hline & KI + Shel & $1.21 \mathrm{E} 05$ & $6.96 \mathrm{E} 05$ & 4.97E-06 \\
\hline & $\begin{array}{l}\text { KI + Shel. + } \\
\text { Evac. }\end{array}$ & $1.71 \mathrm{E} 04$ & $7.81 \mathrm{E} 04$ & 4.97E-06 \\
\hline \multirow{3}{*}{$0.0-50$} & None & $4.63 \mathrm{E} 05$ & $1.75 \mathrm{E} 06$ & $1.11 \mathrm{E}-04$ \\
\hline & KI + Shel & $2.06 \mathrm{E} 05$ & $8.40 \mathrm{E} 05$ & $4.85 \mathrm{E}-04$ \\
\hline & $\begin{array}{l}\mathrm{KI}+\text { Shel. + } \\
\text { Evac. }\end{array}$ & 8.66Е04 & $2.43 \mathrm{E} 05$ & $3.32 \mathrm{E}-04$ \\
\hline
\end{tabular}

\subsection{Computational aids and maps}

The analyses performed as part of PSA level 3 analyses were used to provide quick assessment tools for the radiological situation around the site in case of a postulated accident. These tools help to fulfil the legal requirements of NPP Goesgen defined by law [13]. Two important aids are available. From MELSIM calculations, for each PDS, defined as a combination of a specific containment damage state and a specific core damage state, a realistic and conservative release source term is calculated. The definition of PDS, in general, follows the approach developed by EPRI [14] with additional consideration of containment releases via the filtered venting system, which is not available in US Pressurized Water Reactor (PWR) designs. The results of the calculations are tabulated. The determination of PDS is part of the working procedures of the technical support centre of the plant in case of an emergency. The pre-calculated source terms allow performing a quick estimate of radioactivity releases in case of an accident. This information is supplied to the ENSI and to the National Alarm Centre. Based on the actual weather conditions, these governmental agencies perform an estimate of the possible radiological consequences. This allows them to decide on a timely implementation of offsite emergency actions in an accident situation.

The WINMACCS calculations are used to perform bounding assessments for the most critical weather scenarios with respect to land contamination and expected average radiation dose for an individual person of the population in a specific area. This information is mapped into geographical maps. Examples are shown below. Figure 5 shows the radiation dose for an average individual in the 5-km zone around the plant. Figure 6 shows the intervention levels defining different offsite emergency actions in the $5-\mathrm{km}$ zone around the plant. This 


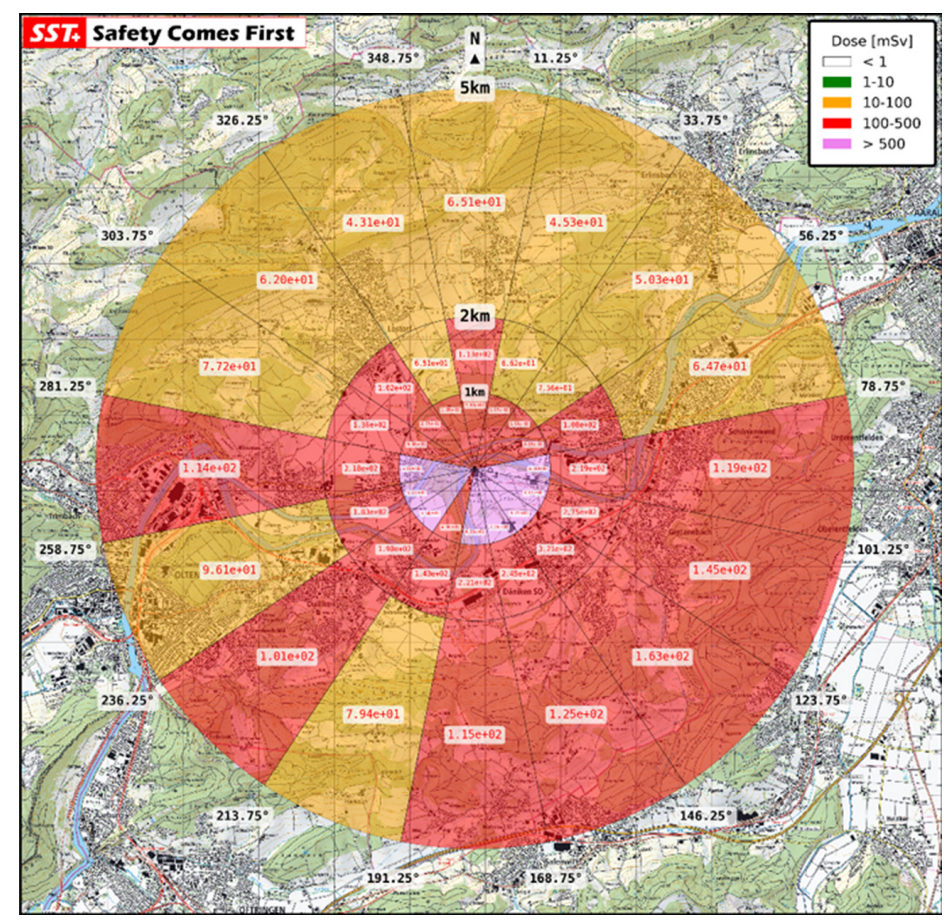

Figure 5: Average radiation dose for the most critical release scenario (RUN03).

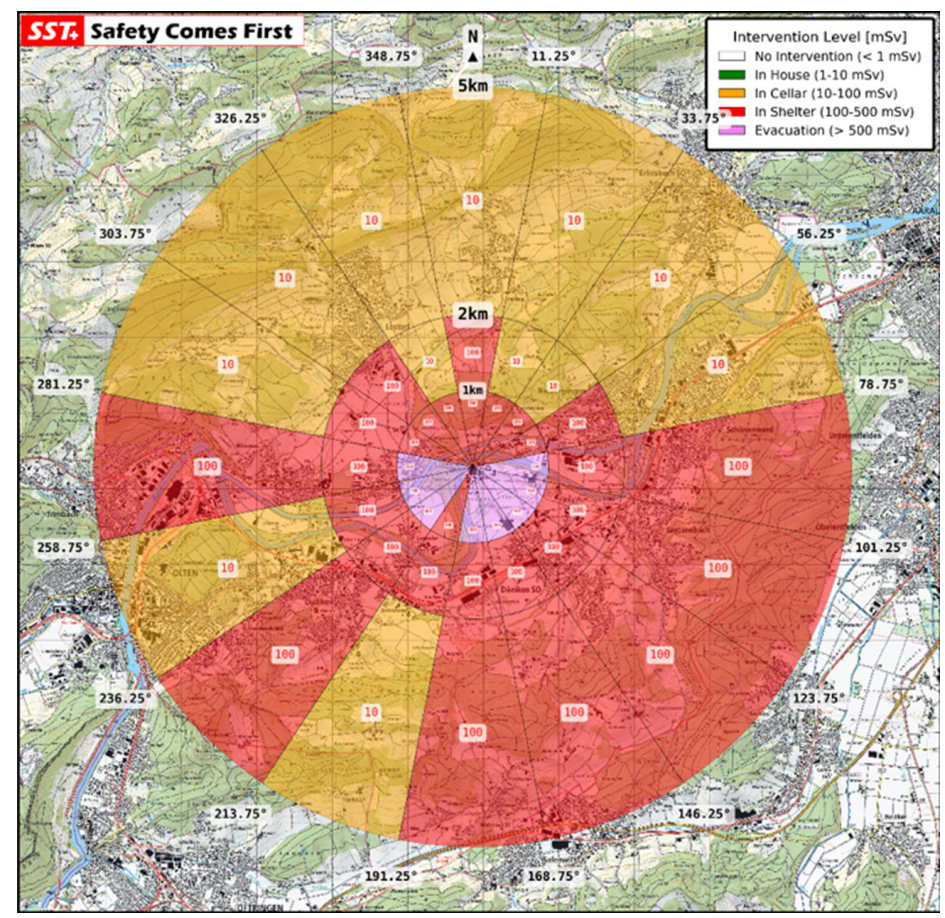

Figure 6: Emergency intervention levels for the most critical scenario (RUN03). 
information is used if a quick estimate of the possible radiological consequences in an early accident phase (immediately after release) is needed or the external communication to governmental agencies is not available.

\section{CONCLUDING REMARKS}

Methods and results of the NPP Goesgen plant-specific PSA level 3 were used to develop tools and simple cartographic aids to support emergency management planning of the nuclear power plant in case of a severe accident. This represents a unique application of probabilistic safety assessment for industrial nuclear power plants. The implementation of this approach and the resulting supporting information allow for replacing the usually more general considerations used for emergency management planning by means of plant- and area-specific technical information.

On the other hand, the updated PSA level 3 for the Goesgen nuclear power plant demonstrated the low risk of nuclear power operation as well as the possible benefit of offsite emergency management in case of postulated, very severe accident situations.

\section{REFERENCES}

[1] Farmer, F.R., Siting Criteria - a new approach. Containment and Siting of Nuclear Power Plants, Vienna, IAEA, pp. 303-323, 1967.

[2] US NRC, Reactor Safety Study. An Assessment of Accident Risks in U.S. Commercial Nuclear Power Plants, WASH-1400 (NUREG 75/014), 1975.

[3] Kaplan, S. \& Garrick, B.J., On the quantitative definition of risk. Risk Analysis, 1(1), pp. 11-27, 1981. https://doi.org/10.1111/j.1539-6924.1981.tb01350.x

[4] U.S. Nuclear Regulatory Commission, Use of Probabilistic Risk Assessment Methods in Nuclear Regulatory Activities, Final Policy Statement, Federal Register Vol. 60, No.158, 1995.

[5] IAEA, Determinin the Quality of Probabilistic safety Assessment (PSA) for Applications in Nuclear Power Plants, TECDOIC-1511,» IAEA, Vienna, 2006.

[6] IAEA, Attributes of Full Scope Level 1 probabilistic Safety Assessment (PSA) for Applications in Nuclear Power Plants, TECDOC-1804, Vienna, 2016.

[7] ABS Consulting, RISKMAN for Windows, Version 15.0 User Manual, 2017.

[8] Sandia National Laboratory, MELCOR Computer Code Manuals, NUREG/CR-6119, SAND2001-0929P, 2001.

[9] Klügel, J.-U., Steiner, P. \& Askari, B., Full-Scope PSA Level 3 of NPP Goesgen - Methods and Results. ANS PSA 2013 International Topical Meeting on Probabilistic Safety Assessment and Analysis, Columbia, SC, 2013.

[10] Sandia National Laboratories, WinMACCS, a MACC2 Interface for Calculating Health and Economic Consequences from Accidental Release of Radioactive Materials into the Atmosphere, User's Guide and Reference Manual, WinMACCS Version 3, 2007.

[11] US NRC, Code manual for MACCS 2: Volume 1, User's Guide, NUREG/CR-6613, SAND97-0594, 1998.

[12] Risk Management Associates, Kernkraftwerk Goesgen, MELSIM_KKG Model Documentation, RMA, San Diego, 2006.

[13] Swiss Federal Government, Verordnung über den Notfallschutz in der Umgebung von Kernanlagen (Notfallschutzverordnung, NFSV), SR 732.33, 2018.

[14] EPRI, Severe Accident Management Guidance Technical Basis Report, TR 1025295, 2012. 